\title{
ERRATUM
}

\section{Cloning and Characterization of a Gene Cluster Involved in Cyclopentanol Metabolism in Comamonas sp. Strain NCIMB 9872 and Biotransformations Effected by Escherichia coli-Expressed Cyclopentanone 1,2-Monooxygenase}

Hiroaki Iwaki, Yoshie Hasegawa, Shaozhao Wang, Margaret M. Kayser, and Peter C. K. Lau

\author{
Biotechnology Research Institute, National Research Council Canada, Montreal, Quebec H4P 2R2, \\ and Department of Physical Sciences, University of New Brunswick, Saint John, New Brunswick \\ E2L 4L5, Canada, and Department of Biotechnology, Faculty of Engineering \\ and High Technology Research Center, Kansai University, \\ Suita, Osaka 564-8680, Japan
}

Volume 68, no. 11, p. 5671-5684, 2002. Page 5680: Footnote $e$ of Table 3 should read "Optically active compound $[\alpha]_{\mathrm{D}}{ }^{25}-10.8^{\circ}$ (c1.9 $\mathrm{CH}_{2} \mathrm{Cl}_{2}$ ) not resolved on the chiral GC."

Page 5683: Reference 33 should read "Iwaki, H., Y. Hasegawa, M. Teraoka, T. Tokuyama, L. Bernard, and P. C. K. Lau. 2003. Cyclohexanol biodegradation genes: a pathway of opportunities, p. 80-92. In R. A. Gross and H. N. Cheng (ed.), Biocatalysis in polymer science. American Chemical Society, Washington, D.C." 